\title{
A rentabilidade da aplicação da Estrutura Discursiva Narrativa em Redação Publicitária
}

\section{The profitability of the application of the Narrative Discourse Structure in Advertising Writing}

DOI: $10.46814 / 1$ ajdv3n1-020

Recebimento dos originais: $30 / 10 / 2020$

Aceitação para publicação: 23/12/2020

\section{Profa ${ }^{\text {. Dra }}$. Marina A. E. Negri}

Doutora em Artes \& MultiMeios pelo Instituto de Artes da Universidade Estadual de Campinas - IA UNICAMP. Professora de Faculdades de Comunicação Social de São Paulo - SP.

E-mail: negri.marina@gmail.com

\section{RESUMO}

Considerada a riqueza formal da Estrutura Discursiva Narrativa enquanto ferramenta verbal apta ao registro de acontecimentos ou à contação de histórias em qualquer plataforma, este Artigo propõe-se a discutir o uso restrito que dela faz a Redação Publicitária, mormente a observada em curso na contemporaneidade. A despeito da multiplicidade de recursos dos quais dispõe a Estrutura Narrativa, é instigante verificar uma paradoxal subutilização desse aparato nos textos da maior parte dos anúncios veiculados atualmente. A constatação da reincidência de tal padrão na Publicidade brasileira levanta uma questão provocativa, dentre outras tantas cabíveis nesse recorte analítico: a pertinência da crença de que, para conseguir ser lido pelos públicos-alvo, o texto publicitário deve ser sempre curto e simplificado.

Palavras-Chave: Estruturas Discursivas, Narrativa, Conflito, Redação Publicitária.

\begin{abstract}
Considering the formal richness of the Narrative Discursive Structure as a verbal tool capable of recording events or telling stories on any platform, this Article proposes to discuss the restricted use of it by the Advertising Editorial Staff, especially the one observed in contemporary times. Despite the multiplicity of resources available to the Narrative Structure, it is instigating to verify a paradoxical underutilization of this apparatus in the texts of most of the advertisements currently broadcast. The verification of the recurrence of such a pattern in Brazilian Advertising raises a provocative question, among so many others that can be addressed in this analytical section: the pertinence of the belief that, in order to be read by the target audiences, the advertising text must always be short and simplified.
\end{abstract}

Keywords: Discursive Structures, Narrative, Conflict, Advertising Writing.

\section{NARRAÇÃO EM DEFINIÇÃO: INFLEXÕES TEÓRICAS}

Colocando-se em perspectiva comparativa as características formadoras das outras duas Estruturas Discursivas Formais - a Descritiva e a Dissertativa -, é possível observar no escopo da Estrutrura Narrativa a complexidade mais aguda de sua natureza. Atribuída a ela, informalmente, a 
função de 'contar uma história', ou 'elencar uma sucessão de fatos', a Narração, vista sob a ótica teórica, encerra em si competências sofisticadas, tais como: movimentação simultânea de pelo menos cinco elementos-chave (obrigatória para a arquitetura do enredo); dimensionamento temporal (necessário para a implementação de ritmo ao encadeamento das ações); intensidade dramática (decisiva para a captação de crescente expectativa ao longo do desenvolvimento da trama).

Os cinco elementos, ora mencionados, que conferem materialidade ao texto narrativo reconhecem-se por: Narrador (formalizado em três categorias enunciativas); Personagens (subdivididos em três escalas de participação); Conflito (tipificado em quatro possibilidades de deflagração); Tempo (decorrido em duas formas de dimensão); Espaço (demarcado em duas formas de ambientação). A operação conjunta desses elementos forma o Enredo, ou corpo da Narrativa. Essencial assinalar que a presença de um Conflito ${ }^{1}$ será sempre a premissa identificatória e legitimadora do discurso narrativo.

Quadro 1: Elementos formadores da Estrutura Narrativa.

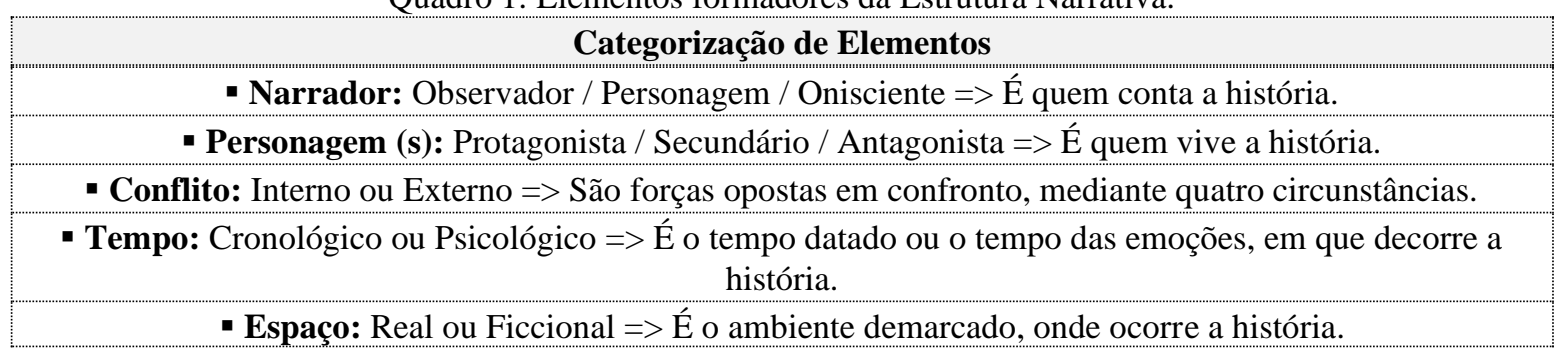

Quadro 2: Tipologia de Conflitos.

\begin{tabular}{|c|c|c|}
\hline Tipos de Conflito \\
\hline I. Externos $=$. \\
\hline Personagem [1] x Personagem [2] \\
\hline Personagem [1] x Personagens \\
\hline Personagem [1] x Mundo \\
\hline II. Interno =>. \\
\hline Personagem [1] x Personagem [1]
\end{tabular}

\footnotetext{
${ }^{1}$ Conflito, desestabilização ou quebra de uma rotina é o chamado leit motiv, ou motivo real da existência de uma narrativa no plano concreto, e ao qual ela se subordina. Conflitos não são circunstâncias necessariamente negativas; são fatos com calibre suficiente para alterar uma dada situação. É a presença do Conflito que faz uma história ser contada a alguém, em busca de atrair a total atenção desse interlocutor e causar-lhe emoção. Admite-se como significado de Conflito a ocorrência simultânea de forças opostas, que têm um início, intensificam-se com o passar do tempo, culminam em um clímax, e finalmente chegam a um desfecho. Desfechos, por sua vez, não são finalizações necessariamente ideais, róseas ou felizes para Conflitos instaurados; são, na verdade, soluções para encerrá-los tanto por bem, como por mal.
} 


\section{ESTRUTURAS DISCURSIVAS DESCRITIVA, NARRATIVA E DISSERTATIVA: BREVES DISTINÇÕES FORMAIS}

O que se deseja na elaboração de uma Descrição, seja ela subjetiva ou objetiva, é a construção verbal de dado objeto, para entendimento efetivo do receptor. O ponto de vista do enunciador da Descrição será revelado por meio dos traços que ele selecionar para a qualificação do objeto a ser descrito.

Sendo a Descrição comumente entendida como uma fotografia verbal, ou flash de certo objeto, a Narração pode ser admitida tecnicamente como um filme verbal, ou sequência contínua de atos; uma história que se desenrola motivada por um fato desestabilizador, e que, por isso, deve ser contada. A fim de ser caracterizada como tal, a Narração precisa e depende desse Conflito detonador, já que um encadeamento de ações, por si só, mesmo com a ativação do eixo temporal, não configura de fato uma Narração, mas sim, um mero Relato. (NEGRI, 2010). No Relato, não obstante se apresente uma progressão de ações, não se detecta em nenhum momento a presença de um Conflito.

Se a marca principal da Descrição é a estaticidade do discurso /relações de simultaneidade/; e a da Dissertação, é a subordinação da rede de ideias que fundamenta um ponto de vista sobre certo tema, /relações de coerência e persuasão/; a marca principal da Narração é a transformação de uma dada situação em outra /relações de anterioridade e posterioridadel. (NEGRI, 2010). A linha do tempo, neste caso, será manipulada do início ao fim do texto, e o estado primeiro dos elementos componentes, a citada /anterioridadel, (o antes) haverá de ser transformado até o seu desfecho, ocasionando uma nova situação, a citada /posterioridadel, (o depois).

Na Narração, discurso notadamente dinâmico, os participantes da história, a princípio dispostos em um panorama determinado $=>/ a /$, são levados a uma modalização distinta da inicial => /b/. À efetiva transformação das bases embrionárias da trama para um quadro diferente ao seu término denomina-se narratividade, índice possível de ser estabelecido igualmente em textos não narrativos, a exemplo da Dissertação. "A narratividade é um componente que pode existir em textos que não são narrações. A narratividade é a transformação de situações”. (PLATÃO \& FIORIN, 1996 - p. 87).

\section{A EDULCORAÇÃO dO CONFLITO NA NARRATIVA PUbLiCitária: A OBRIGATORIEDADE DO FINAL FELIZ}

Em face de tais pressupostos teóricos, este trabalho tenciona enfocar a constatação de que na prática adotada pela seara publicitária, entretanto, (salvaguardando-se poucas memoráveis exceções, como se documentará mais adiante), o Conflito presente nos anúncios de envergadura narrativa revelase, em geral, um Conflito de Superfície, muitas vezes barateado ao extremo, com a presumível finalidade de encaminhar a trama publicitária a um desfecho inequivocamente positivo, não raro, banal 
ou mesmo inverossímil, o qual se restringe ao uso do produto / serviço / marca anunciante respondendo às demandas e prometendo felicidade ao consumidor.

Pequenos dramas do dia-a-dia, como a fome fora de hora, a busca da forma física, um cabelo oleoso, uma pele áspera, uma roupa manchada, uma cólica ou dor de cabeça, entre outros correlatos, são todos solucionáveis por meio da aquisição de um produto / serviço, talhados sob medida para sanar tais dificuldades ou Conflitos. Desdobrados sob a forma de Narrativas do cotidiano, esses tipos de tramas ligeiras, em geral com 30 segundos de duração em meios eletrônicos ortodoxos, como rádio e televisão ${ }^{2}$, e uma página em revistas, ganham frequentemente uma resolução por demais plausível, repetitiva e desnecessariamente infantilizada, que desemboca em um desfecho indelevelmente positivo. No meio digital, são ainda mais reduzidas e cada vez menos verbais.

Figura 1: Anúncios pág. simples para Subway e Chocolates Nestlé: respostas imediatas à demanda pela felicidade momentânea.

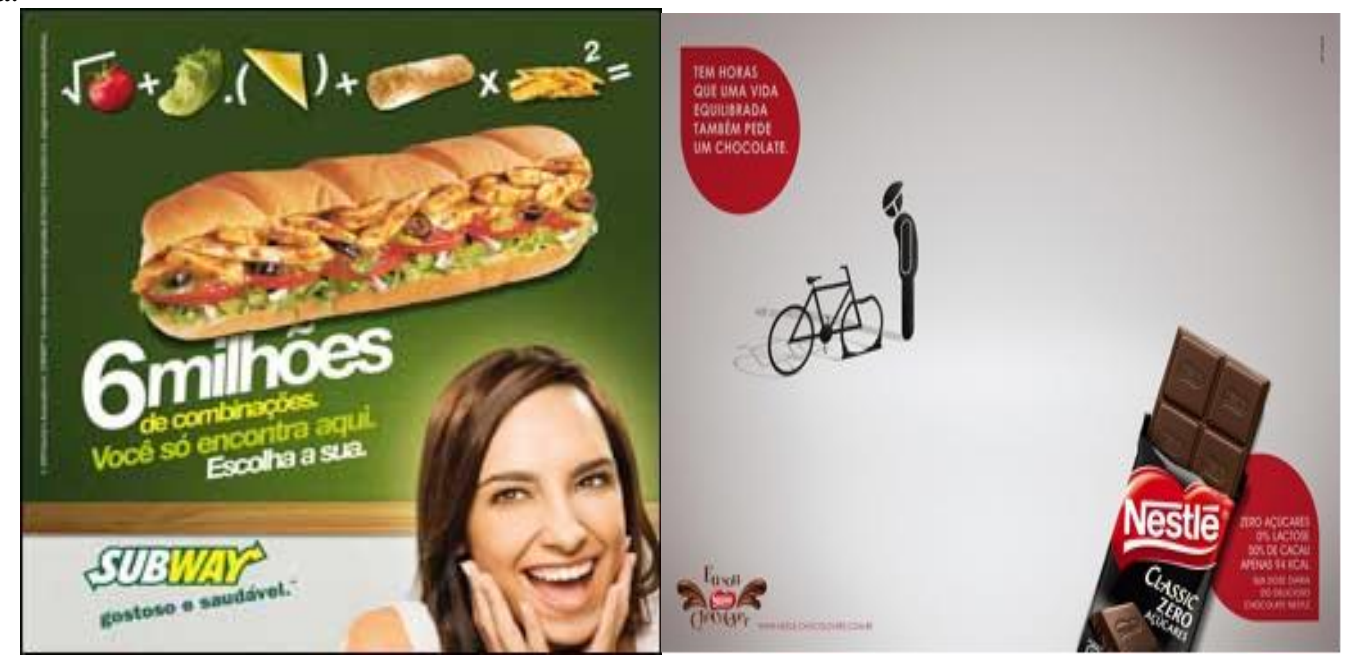

Mesmo que a Narrativa comece com a representação de um conflito / situação-problema a ser resolvido, o produto / serviço / marca encarregar-se-á de restabelecer a ordem, reorganizando a realidade, trazendo de volta o equilíbrio. Não há, na Publicidade, histórias sem finais felizes, ao contrário, por exemplo, do Jornalismo. Aqui reside sua magia: todo o possível e o impossível se realizam para levar o público-alvo à felicidade, ainda que simulada. (FLAUSINO \& MOTTA, 2007 - p. 163).

Nessa intervenção, extraída de Artigo publicado pelos pesquisadores brasileiros Márcia Flausino e Luiz Motta, vê-se que ambos recorrem ao termo 'magia' para qualificar, em sua visão, a função precípua da Publicidade. A mesma expressão foi eleita pelos pesquisadores nórdicos Torben

\footnotetext{
${ }^{2}$ Filmes comerciais com características de fragilidade no enredo narrativo. Anunciantes respectivamente: Tylenol, Instituto Mauá de Tecnologia e Pepsi. Acesso aos 13-05-2015 em: https://www.youtube.com/watch?v=_74Dxm6NyQk https://www.youtube.com/watch?v=pW_MeKQQZUc https://www.youtube.com/watch?v=po0jY4WvCIc\&list=PL8E8573BFB464D054
} 
Vestgaard e Kim Schröeder como metáfora explicativa para a ratificação do procedimento de descolamento da realidade, próprio do discurso publicitário, a qual está exposta em seu livro $A$ Linguagem da Propaganda. Na obra, sustentados por um arcabouço de ordem sociológica, eles se referem à Propaganda como fosse ela um ‘espelho mágico', por meio do qual seriam sublimadas todas as frustrações cotidianas do homem comum.

A Propaganda se torna assim, um espelho mágico, no qual uma interpretação mais sutil nos permite discernir os contornos do generalizado descontentamento popular com a vida cotidiana e com as oportunidades que nos proporciona a sociedade em que vivemos. Portanto, a Propaganda fundamenta-se no desejo subconsciente de um mundo melhor. (VESTGAARD \& SCHRÖEDER, 2004 - p. 183).

Figura 2: Slogans atuais de Coca-Cola e Kibon correlacionam consumo a felicidade.
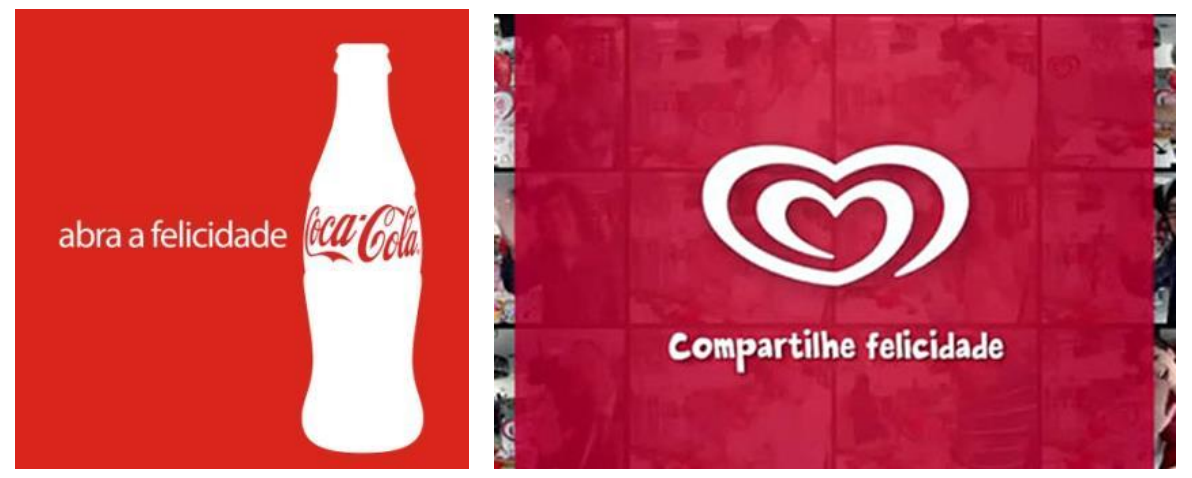

Uma vez mais utilizada, agora sob a ótica crítica da filósofa Márcia Tiburi, a analogia da palavra 'mágica' com a Publicidade contrapõe-se à visão dos autores ora citados e recebe um desdobramento negativo, ao relacionar falsamente, de acordo com a filósofa, a prometida 'felicidade publicitária' à ilusão, à fuga da realidade, à insatisfação crônica e à mentira.

A felicidade publicitária apresenta-se como mágica dos gadgets eletrônicos que se acionam com um toque, dos "amigos" virtuais que não passam de má ficção. A felicidade publicitária está ao alcance dos dedos e não promete um depois. Ilude que não há morte e com isso dispensa do futuro. Resulta disso a massa de "desesperados" trafegando como zumbis nos shoppings e nas farmácias do país em busca de alento. (TIBURI, M., Revista Cult, 2011 - Ed. 139)³.

\footnotetext{
${ }^{3}$ Website da Revista Cult - Ed. 139, 2011, acessado aos 12-05-2015, em:

<http://revistacult.uol.com.br/home/2011/07/industria-cultural-da-felicidade/>
} 
Figura 3: Anúncio pág. simples de lançamento do I-Phone 5: a novidade tenta garantir a felicidade.

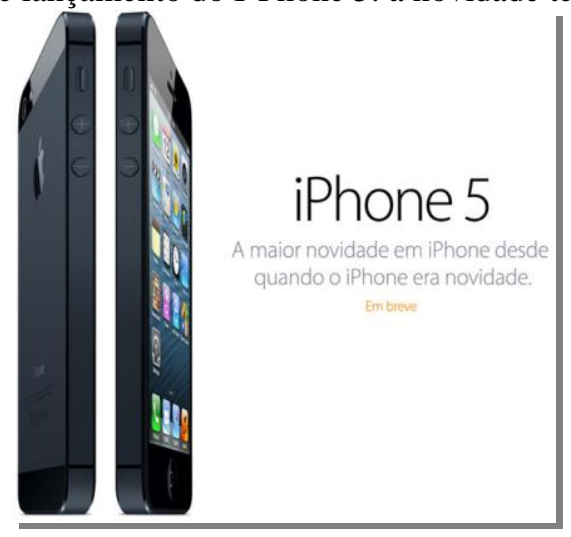

\begin{abstract}
Mas, o que dizer da qualidade intrínseca dos textos, concebidos para veículos, suportes e públicos diversos? O que pensar das evidentes diferenças estilísticas, sintáticas e semânticas nos diversos tipos, modos e formatos textuais, produzidos para além do impresso? Não se pode desprezar que há diferenças entre os "níveis de linguagem" e que elas constituem a heterogeneidade das pessoas e seus modos de fala e apropriação dos gêneros discursivos. Negar a diferença é negar o óbvio e servir ao ecletismo. Em situações de assimetria social, cultural e econômica, frequentemente isso nos leva a nivelar rasteiramente o que tem características e procedimentos próprios. Bastaria percorrer as milhares de referências, de Aristóteles, quatro séculos antes de Cristo, a Francis Vanoye, na década de 1970, para recordar a lição milenar de que o texto trata de um assunto, de acordo com determinado estilo e gênero, conforme o efeito que se pretenda produzir em nosso auditório, seja ele particular ou universal (PERELMAN, 1997 Apud CHAUVIN, J. P.2020).
\end{abstract}

A questão torna-se ainda mais complexa se a ela for acrescida a visão macroscópica do sociólogo francês Jean Baudrillard, ao advertir que não adianta resistirmos à Publicidade. À medida que resistimos, tornamo-nos mais sensíveis à sua existência, tanto como produto de consumo quanto manifestação de uma cultura. (Apud DRIGO, 2008).

\title{
4 O USO CAPITALIZADO DA ESTRUTURA NARRATIVA NA REDAÇÃO PUBLICITÁRIA: OS CASOS SHOPPING CENTER IGUATEMI E KOMBI
}

Pontos de vista à parte, quando na Publicidade verbal se percebe a inteligente aplicação da Estrutura Narrativa, mesmo a questão relativa à infalível promessa de felicidade através da aquisição de um produto - tese discutível e, hoje, severamente combatida -, parece mesmo minorada, como se pode perceber na reprodução textual do seguinte anúncio impresso, idealizado para o lendário e ultra sofisticado Shopping Center Iguatemi, nos idos 1999.

\section{Relógio do Shopping Iguatemi}

Ele se perguntava por que nunca tinha tempo para ficar com o filho.

Pai, como funciona este relógio?...

\footnotetext{
${ }^{4}$ Fragmento literal extraído do Artigo: Leitura Fragmentária: Premissas e Implicações, de Jean Pierre Chauvin, publicado no Latin American Journal of Development, Curitiba, v.3, nº 1, p.137-146, jan./fev.2021 - ISSN 2674-9297.
} 
Tá vendo a água em cima daquela bola?...

Ele ia explicando, e o garoto, maravilhado com o relógio.

Mas, para que serve o tempo, pai?

Como é que as crianças conseguem fazer esse tipo de pergunta?

Tempo serve para medir as coisas que a gente faz.

A hora de acordar, de dormir. Daqui a pouco, por exemplo, eu tenho que te deixar na casa da sua mãe.

Ele esperava o tradicional por quê? Mas o garoto não fez a pergunta.

Devia estar se acostumando. Devia estar crescendo.

Engraçado como as crianças crescem rápido.

Do telefone celular, ligou primeiro para a ex-mulher, depois para a empresa.

Comprou dois sorvetes e ficaram horas sentados, sem pressa,

olhando o relógio d'água do Shopping Iguatemi.

Narrado em $3^{\text {a }}$ ps. sing. por um Narrador Onisciente, a peça exibe traços escriturais requintados e sobremaneira incomuns na Redação Publicitária, tanto naquele espectro temporal como no de agora: Enredo alinear; Tempo psicológico; Discurso indireto livre; Conflito baseado em um recém-admitido sentimento de culpa, na percepção do pai, por manter pouco convívio com o filho. Trata-se, neste caso, de um conjunto de elementos narrativos muito bem articulado, certamente mais notório na Literatura, porém, com perfeita aplicabilidade na Publicidade, além de ser forte o bastante para atrair a atenção do público-alvo e favorecer a memorização da marca, conforme se busca demonstrar neste estudo.

Todas essas prerrogativas em concomitância ganham valor e fôlego adicional, se for considerado o fato de que a cena criada, a um só tempo, afetuosa e complexa, serviu para divulgar subliminarmente a imagem de um dos mais seletivos e caros templos de consumo da América do Sul. A aura emocional, desencadeada pelos sentimentos dos personagens pai e filho, em contraste com a frieza mercadológica do produto anunciante possibilitou uma antítese inesperada, responsável por provocar a empatia necessária com o receptor, beneficiando, assim, a marca Shopping Center Iguatemi.

Num significativo deslocamento cronológico - do final da década de 90 para 2014 -, é oportuno identificar a mesma destreza redacional, desta vez na celebrada campanha de Deslançamento da Kombi - utilitário da Volkswagen do Brasil, que fez história na memória afetiva do país.

Através da opção bem calculada pelo recurso persuasivo Dramaticidade, (o mesmo empregado no anúncio do Shopping Center Iguatemi), a peça em questão apresenta outros elementos de boa capilaridade textual, tais como: Narrador Personagem, em $1^{\mathrm{a}}$ ps. sing.; Enredo Linear; Discurso direto; e um Conflito que se funda sobre a doída despedida do veículo dos consumidores brasileiros.

Com um Título beirando o Humor e o Trocadilho amalgamados em grau discreto: Vai aí a Kombi. Em breve, em nenhuma concessionária perto de você, a agência ALMAP BBDO - SP fez o inédito lançamento da campanha de Deslançamento do veículo, gerando assim, um intenso residual de lembrança, por ter chamado grandemente a atenção de todos os públicos, devido à força desse competente jogo de palavras e intenções. 
Figura 4: Anúncio narrativo pág. simples, parte da Campanha Os últimos desejos da Kombi - 2014 / Brasil.

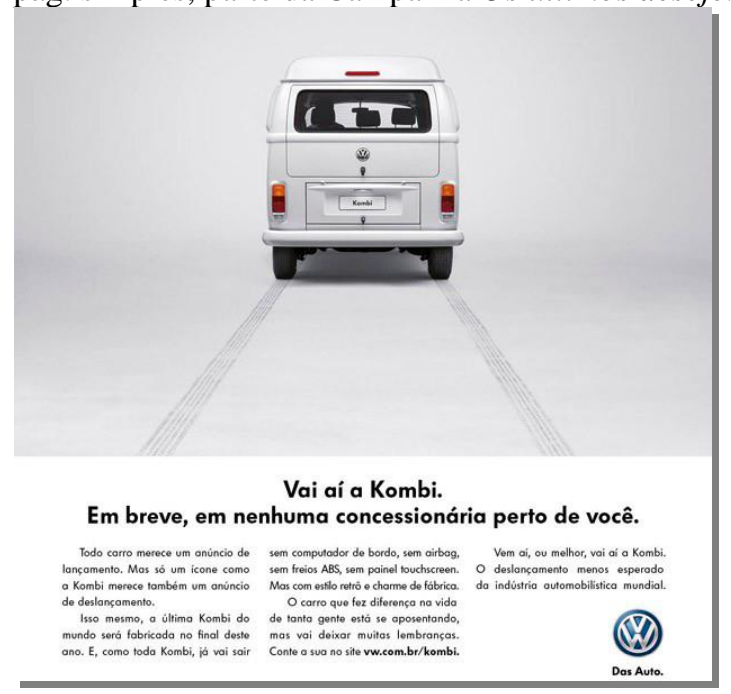

Em ritmo equilibrado, sem sobressaltos, o próximo anúncio da campanha, premiado por várias entidades, está firmado sobre um texto narrativo longo, bem cadenciado, em formato de uma carta testamento, no qual a Kombi revive sua trajetória de vida, seus mais pungentes momentos e se despede de forma suavemente dramática do povo brasileiro, legando alguns presentes àqueles que lhe foram mais caros. Desse modo, forja um comovente desfecho para a longa e consistente Narrativa, que promete ficar cristalizado na história da Publicidade brasileira.

Veiculado massivamente em suporte eletrônico, digital e impresso, conforme reproduzido a seguir, os quinze últimos atos de despedida da Kombi fecham a história com uma hábil alternância mais uma vez no uso dos recursos Humor e Dramaticidade, combinados.

Figura 5: Anúncio narrativo pág. dupla, parte da Campanha Os últimos desejos da Kombi-2014 / Brasil.

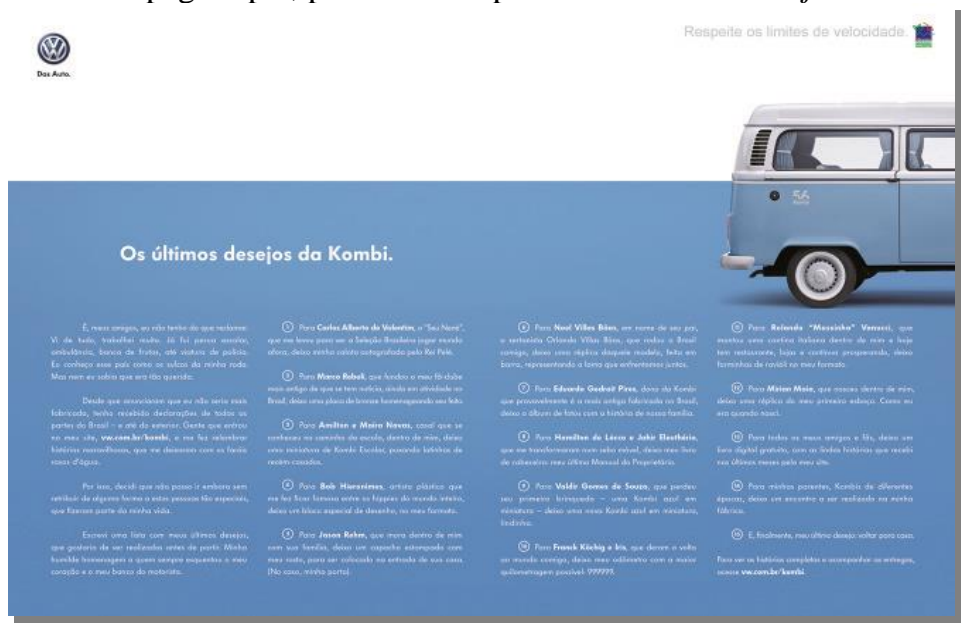

(...)

1) Para Carlos Alberto de Valentim, o "Seu Nenê", que me levou para ver a Seleção Brasileira jogar mundo afora, deixo minha calota autografada pelo Rei Pelé. 2) Para Marco Rebuli, que fundou o meu fã-clube mais antigo de que se tem notícia, ainda em 
atividade no Brasil, deixo uma placa de bronze homenageando seu feito. 3) Para Amilton e Maíra Navas, casal que se conheceu no caminho da escola, dentro de mim, deixo uma miniatura de Kombi Escolar, puxando latinhas de recém-casados. 4) Para Bob Hieronimus, artista plástico que me fez ficar famosa entre os hippies do mundo inteiro, deixo um bloco especial de desenho, no meu formato. 5) Para Jason Rehm, que mora dentro de mim com sua família, deixo um capacho estampado com meu rosto, para ser colocado na entrada de sua casa. (No caso, minha porta). 6) Para Nel Villas Bôas, em nome de seu pai, o sertanista Orlando Villas Bôas, que rodou o Brasil comigo, deixo uma réplica daquele modelo, feita em barro, representando a lama que enfrentamos

juntos.

7) Para Eduardo Gedrait Pires, dono da Kombi que provavelmente é a mais antiga fabricada no Brasil, deixo o álbum de fotos com a história de nossa família. 8) Para Hamilton de Lócco e Jahir Eleuthério, que me transformaram em um sebo móvel, deixo meu livro de cabeceira: meu último Manual do Proprietário. 9) Para Valdir Gomes de Souza, que perdeu seu primeiro brinquedo - uma Kombi azul em miniatura -, deixo uma nova Kombi azul em miniatura, lindinha. 10) Para Franck Köchig e Iris, que deram a volta ao mundo comigo, deixo meu hodômetro $\begin{array}{llll}\text { com a maior } & \text { quilometragem } & \text { possível: } & 999 .\end{array}$ 11) Para Rolando "Massinha" Vanucci, que montou uma cantina italiana dentro de mim e hoje tem restaurante, lojas e continua prosperando, deixo forminhas de ravióli no meu formato. 12) Para Mirian Maia, que nasceu dentro de mim, deixo uma réplica do meu primeiro esboço. Como era quando nasci. 13) Para todos os meus amigos e fãs, deixo um livro digital gratuito, com as linhas histórias que recebi nos últimos meses pelo meu site. 14) Para minhas parentes, Kombis de diferentes épocas, deixo um encontro a ser realizado na minha 15) E, finalmente, meu último desejo: voltar para casa ${ }^{5}$.

fábrica.

Em todos os meios de comunicação em que foi divulgado, esse texto de tom visivelmente emocional provocou repercussão positiva em relação à marca e trouxe à tona a relação afetiva que o consumidor brasileiro manteve com a Kombi, ao longo de sua presença de décadas nas ruas do país, transfigurando-se em tantas variantes de mobilidade, que mal se podem elencar. Mérito credenciado ao fato de ter sido essa uma história teórica e mercadologicamente bem contada, por meio de recursos narrativos ricamente organizados no decorrer da trama, que encenam o Conflito $=>$ Encerramento da produção do veículo no Brasil. O arranjo criativo consegue o paradoxo de cristalizar a imagem da Kombi no memorial do brasileiro no justo momento em que ela deixa definitivamente a cena.

\section{5 ÚLTIMAS CONSIDERAÇÕES}

Em vista da utilização, de certa forma, modesta e restritiva da Estrutura Discursiva Narrativa, enfocada para análise no presente Artigo, buscou-se, como intenção primária, colaborar em alguma medida para melhor observação e estudo de sua prática aplicada à Redação Publicitária.

A breve seleção aqui apresentada como fundamentação, composta por exemplos bem sucedidos, veiculados tanto em tempos passados, como no presente, registra e enaltece a escolha ousada

\footnotetext{
${ }^{5}$ Texto em parte extraído do website Carpress, aos 12-05-2015 em:

<http://carpress.uol.com.br/noticias/item48153.shl>
} 
e acertada dos redatores responsáveis, por elementos sofisticados e de risco para a formalização de um anúncio, como por exemplo, o Discurso Indireto Livre e o Narrador Onisciente, ambos de delicada operacionalização. Demonstrada sua eficácia tanto para a beleza estética das peças, como para a possibilidade da produção de sentido, ativação do imaginário do público-alvo e sobrevalorização das marcas anunciantes, compreende-se que uma mais acurada execução verbal só traria ganhos ao plano escrito da Criação Publicitária.

Contar histórias é excelente maneira de se perpetuar mensagens, especialmente se elas forem capazes de desencadear sentimentos. É esse o objetivo e a métrica que delineia a Storytelling, palavra de ordem no cenário vigente da Publicidade e da Propaganda da atualidade, uma arma verbal, a rigor, derivada do arsenal teórico exposto neste trabalho. 


\section{REFERÊNCIAS}

DONDIS, Donis. A sintaxe da linguagem visual. São Paulo: Ed. Martins Fontes, 2007.

DRIGO, Maria Ogécia In: A Publicidade na perspectiva de Baudrillard. Revista Comunicação, Mídia e Consumo, Vol. 5, No 14 - 2008 - Comunicação e Cidadania ESPM São Paulo - SP.

FLAUSINO, Marcia. C. \& MOTTA, Luiz G. Break comercial: pequenas histórias do cotidiano. Narrativas publicitárias na cultura da mídia. Revista da Comunicação, Mídia e Consumo, Vol. 4, $\mathrm{N}^{\circ} 11$ - p. 159-176, 2007.

FRIEDMAN, Norman. Point of View in Fiction: The Development of a Critical Concept. PMLA, Vol. 70, No 5 (Dec., 1955) - p. 1160 -1184. DOI: 10.2307/459894.

LEITE, Ligia Chiappini Moraes. O foco narrativo (ou A polêmica em torno da ilusão), p. 25-70. São Paulo: Ed. Ática, Série Princípios, 1985.

NEGRI, Marina. Contribuições da Língua Portuguesa para a Redação Publicitária. São Paulo: Ed. Cengage Learning, 2010.

PERELMAN, C. Retóricas. Tradução: Maria Ermantina Galvão G. Pereira. São Paulo: Ed. Martins Fontes, 1997.

PLATÃO \& FIORIN. Lições de texto: Leitura e Redação. São Paulo: Ed. Ática, 1996.

SUBIRATS, E. A existência sitiada. Tradução: Flávio Coddou. São Paulo: Ed. Romano Guerra, 2010.

VANOYE, F. (2003). Usos da linguagem: problemas e técnicas na produção oral e escrita. $12^{a}$ ed. São Paulo: Ed. Martins Fontes, 2003.

VESTGAARD, Torben \& SCHRÖEDER, Kim. Linguagem da Propaganda. São Paulo: Ed. Martins, 2004.

\section{ARTIGO}

Leitura Fragmentária: Premissas e Implicações, de Jean Pierre Chauvin, publicado no Latin American Journal of Development, Curitiba, v.3, nº 1, p.137-146, jan./fev.2021 - ISSN 2674-9297. 